\title{
Liver Transplantation for Hepatocellular Carcinoma: An Appraisal of Current Controversies
}

\author{
Yee Lee Cheah ${ }^{a}$ Pierce K.H. Chow ${ }^{b, c, d}$ \\ a Hepatobiliary and Pancreatic Surgery, Department of Surgery, Khoo Teck Puat Hospital, \\ ${ }^{b}$ General Surgery Department, Singapore General Hospital, ' $\mathrm{Office}$ of Clinical Sciences, \\ Duke-NUS Graduate Medical School Singapore, and dDepartment of Surgical Oncology, \\ National Cancer Center Singapore, Singapore
}

\section{Key Words}

Hepatocellular carcinoma · Liver transplantation

\begin{abstract}
Cost-effective and efficacious approaches to the management of hepatocellular carcinoma (HCC) must be developed in response to the rising incidence of this disease worldwide. While surgical resection is the current standard of care, most patients afflicted with HCC are unresectable at diagnosis. Developing good therapy for these patients is thus imperative. Liver transplantation offers the possibility of extirpation of not only the tumor but also the remaining cirrhotic liver. Transplantation is hence an ideal treatment option for early HCC patients with poor liver function. When transplantation occurs within the established Milan criteria, the outcomes are good (5-year survival $>60 \%$ ). Current efforts are under way to expand the indications for transplantation beyond the Milan criteria. The resulting surge of new algorithms may potentially shape a new system of transplantation criteria based on personalized parameter calculations. However, this change in criteria is not without controversy, and data remains inconclusive. Current bridging strategies have been similarly hindered by lack of consensus because of the lack of randomized, controlled trials demonstrating their efficacy. In addition, debate continues on the role of transplantation in early (resectable) HCC with good liver function. Issues of reimbursement, the paucity of available donor livers, and governmental funding (or lack thereof) continue to complicate the situation. In this review, issues preventing or facilitating globally consistent treatment strategies for HCC are discussed.
\end{abstract}




\section{Introduction}

Surgical resection is considered the primary mode of treatment for hepatocellular carcinoma (HCC). The high risk of perioperative mortality because of complications of portal hypertension and liver failure may preclude liver resection in many patients with advanced hepatic dysfunction. In about $80 \%$ of cases, HCC occurs in cirrhotic livers. Surgical resection in HCC fails to address issues associated with the remnant cirrhotic liver and its continued hepatocarcinogenesis. Thus, the main causes of late mortality after resection include tumor recurrence and chronic liver failure. Recurrence rates at 5 years have been reported to exceed $60 \%[1,2]$ in some studies, and only $10-31 \%$ of recurrences may be re-resectable [3].

The first successful liver transplantation in humans was performed by Thomas Starzl in 1967 [4]. Use of this treatment modality expanded after the introduction of improved immunosuppressive therapy (cyclosporine) in the 1980s [5]. Overall 5-year survival after liver transplantation currently exceeds $70 \%[6,7]$ in selected centers. The early results (1980s) of liver transplantation for HCC were poor, with low overall survival (15\% 5-year survival) and high recurrence $(75 \%)$ rates $[8,9]$. The main cause of these disappointing results was poor patient selection; patients with large tumors associated with vascular invasion and lymph node metastasis often underwent transplantation.

\section{Criteria for Transplantation}

Initial efforts to restrict liver transplantation to patients with smaller tumors culminated in the landmark paper by Mazzaferro et al. in 1996, which recommended limiting eligibility for transplantation to cirrhotic patients with solitary tumors of $\leq 5 \mathrm{~cm}$, no more than three tumor nodules with each being $\leq 3 \mathrm{~cm}$ in diameter, and no macrovascular invasion, now collectively known as the Milan criteria [10]. Actuarial 4-year disease-free and overall survival rates in that study were 83 and $75 \%$, respectively, which were comparable with the results of studies of liver transplantation for other indications and resection of HCC in cirrhotic livers. These results have since been validated by other groups throughout the world [11-14]. In 2011, the original group conducted a systematic review of published literature over 15 years, revealing that patient selection according to the Milan criteria is an independent prognostic factor for outcome after liver transplantation for HCC [15]. A recent international consensus conference (involving 300 experts from 5 continents) recommended the Milan criteria as the current benchmark for the selection of HCC patients for liver transplantation and the basis for comparison with other suggested criteria [16].

Reports from the Organ Procurement and Transplantation Network (OPTN) and European Liver Transplant Registry (ELTR) revealed that 14\% of liver transplantations in Europe and $17.2 \%$ in the United States were performed in patients with HCC [6, 7]. Because many centers have gained increasing experience in transplantation for HCC and have achieved excellent survival results, some investigators have argued that the Milan criteria are too restrictive and that they limit options at a time when the incidence of HCC is increasing. The limitations of imaging techniques in delineating tumor size and number are worsened by the high frequency of under- or overstaging. Accuracy levels of only $60-75 \%$ in preoperative assessments using the Milan criteria have been reported $[10,17,18]$. Furthermore, using only tumor size and number as prognosticators for transplantation in HCC may be inaccurate as vascular invasion has been shown to be the strongest predictor of tumor recurrence and overall survival $[12,19,20]$. No strong linear relationship between tumor size and number and the presence of microvascular invasion has been demonstrated. In addition, microvas- 
cular invasion is not evident in $50 \%$ of patients with tumors $>4 \mathrm{~cm}$ and $53 \%$ of patients with multiple nodules $[12,21,22]$.

At the University of California San Francisco (UCSF), one of the first attempts was made to extend the indications for transplantation modestly beyond the Milan criteria to include single tumors $\leq 6.5 \mathrm{~cm}$ or $2-3$ tumors $\leq 4.5 \mathrm{~cm}$ at the most, with a total tumor diameter $\leq 8 \mathrm{~cm}$ (UCSF criteria) [17]. In a retrospective analysis of the impact of pathologic tumor stage on recurrence-free survival, they described survival rates equivalent to those of patients who underwent transplantation within the Milan criteria. Similar results have been described by other investigators $[13,23,24]$. The main criticisms of the UCSF study were its retrospective nature and the use of post-transplant pathological staging instead of pretransplant imaging staging to justify their criteria for expansion. In a multicenter study in which patients were assigned to groups within and beyond the Milan criteria but within the UCSF criteria, as determined by preoperative imaging, survival rates were lower in the UCSF group, although the difference was not statistically significant [25]. In response to this criticism, the groups from UCSF and the University of California at Los Angeles (UCLA) separately analyzed the same results of transplantation in HCC cases using preoperative imaging as the basis of staging. As a result, 5-year survival rates of $80.9 \%$ (median follow-up 26 months) and $64 \%$ (mean followup 6.6 years), respectively, were recorded using the UCSF criteria $[14,26]$.

Mazzaferro et al. performed a multicenter, retrospective analysis of HCC in Europe and America; this analysis identified a subset of patients selected for transplantation using additional criteria. Survival in these patients was comparable with that in patients transplanted within the Milan criteria [27]. In 1,112 patients selected for transplantation using additional criteria in whom no microvascular invasion was observed on explanted histology, a 70\% 5-year survival rate was recorded. Thus, acceptable survival rates may be achieved if patients fulfill the "up to seven" criteria, which states that the sum of the number of tumor nodule (s) and diameter of the largest tumor must not exceed seven. An algorithm, the "Metroticket Calculator," was then developed to predict survival after liver transplantation for different computations of tumor size, numbers of nodules, and the presence or absence of microvascular invasion [27, 28]. While this algorithm explains the biological basis behind the good survival rates in some individual patients selected for transplantation according to additional criteria, this approach has its limitations. In particular, the study in which the "up to seven" and "Metroticket Calculator" methods were suggested was a retrospective analysis of pathological data that excluded other prognostic parameters such as tumor grade. In addition, current technology is unable to determine the presence of microvascular invasion prior to transplantation.

Tumor grade has been identified as a predictive factor of HCC recurrence $[12,20]$ that correlates significantly with microvascular invasion [12, 21]. Several groups have used tumor grade (via preoperative tumor biopsy) in patient selection for transplantation in addition to the Milan criteria $[29,30]$. The extended Toronto criteria included patients who did not meet the Milan criteria. These criteria included no size or number restrictions; patients were eligible for transplantation as long as their performance status was high and their tumors were not poorly differentiated [29]. However, there was no significant difference in 5-year survival between patients selected within the Milan criteria (72\%) versus those selected within the extended Toronto criteria (70\%). The accuracy of needle-core biopsy in determining tumor grade has been recently reported as $91.4 \%$ with no incidence of tumor seeding $[29,31]$. Thus, the role of tumor grade in patient selection for transplantation awaits further validation. 


\section{Impact of Dropout on Outcome}

All the studies reviewed thus far analyzed outcomes from the time of transplantation rather than the time of patient listing. Patients placed on the waiting list for liver transplantation may drop out because of factors such as death, tumor growth or spread exceeding acceptable limits, and deterioration in clinical status precluding transplant. The rate of dropout is dependent on the waiting time for organ availability; this is highly variable and depends on factors such as geographical region and patient blood group. When patients were analyzed on an intention-to-treat basis (from the time of listing), the dropout rate was found to be $23 \%$ in a region where the mean waiting time was 105 days. Dropout significantly impaired survival; as the waiting time increased from 62 to 162 days, 2-year survival decreased from 84 to $54 \%$ [11]. When survival was adjusted for wait-list drop out, a 10-20\% reduction in patient survival was noted at every time point up to 3 years [32]. Other groups have reported 5-year survival rates of only $51-56 \%$ when outcomes were analyzed on an intentionto-treat basis $[33,34]$. Thus, there is a lack of universal acceptance of indications beyond the Milan criteria, especially in geographical regions with long waiting times for a donor liver.

Most programs currently use bridging strategies, which are neoadjuvant treatments aimed to prevent tumor progression and reduce dropout rates. However, treatment strategies (transarterial chemoembolization, radio-frequency ablation, radioembolization, conformal radiotherapy, sorafenib or combination therapy) are highly dependent on local preferences. Because of the absence of randomized, controlled trials demonstrating the efficacy of bridging therapies in improving intention-to-treat outcomes, no consensus has been reached on the indications for or the type, number, and length of neoadjuvant treatment [35].

\section{Living Donor Liver Transplantation for HCC}

One strategy to overcome deceased organ shortages and long waiting times is to use grafts of partial livers from healthy living donors. In some countries, particularly those in Asia, living donor liver transplantation (LDLT) may be the only option for transplant candidates because of the lack of deceased donors. No significant differences in overall survival between patients receiving LDLT and those receiving deceased donor liver transplantation for HCC have been demonstrated. However, higher recurrence rates were found among "fasttracked" patients in whom transplantation was performed before the innate aggressiveness of the biology of the tumor had been inadequately determined in the period between diagnosis and transplantation [13, 36-38]. This period of observation is inherent in deceased donor transplantation, which may explain lower rates of post-transplant recurrence after this procedure. However, no consensus has been reached on the optimal length of this observation period.

The main controversy in LDLT is the issue of donor safety. Living donor transplantation is unique in that risk and benefit analyses cannot be independently assessed for the donor and recipient but must be balanced between both; this is the concept of double equipoise [39]. The Vancouver Forum, an international consensus conference on the care of organ donors, recommended that LDLT be carried out only if the risk to the donor can be justified by an acceptable outcome in the recipient [40]. The status of living donation as a directed gift in the context of deceased donor organ shortage complicates and at times makes the definition of justifiable risk and acceptable outcome subjective. The busiest centers have reported donor morbidity rates of up to 38\% [41-43]. An international survey of 71 LDLT programs from 21 countries revealed that $77 \%$ of programs have at least one Clavien grade III, IV, or V 
complication among their liver donors. In addition, 3 donors have themselves required transplantation for liver failure, and at least 34 donors have died worldwide [44].

To justify LDLT, survival rates in HCC patients receiving live donor grafts should be similar to those of patients with comparable stage receiving deceased donor grafts. International consensus guidelines recommended that LDLT be restricted to centers with proven track records [16]. Acceptable outcomes in complex liver surgery and liver transplantation using these guidelines must be validated in order to minimize risk to healthy donors and maximize recipient outcomes [16]. Unfortunately, consistent compliance with and regulation of these guidelines have not been realized.

In major practice guidelines, including those of the American Association for the Study of the Liver (AASLD) [45] and the Asia-Pacific Association for the Study of the Liver (APASL) [46], transplantation for HCC within the Milan criteria is advocated in patients with poor liver function who cannot benefit from liver resection. However, it has been suggested that patients with HCC and good liver function should be transplanted because of the likelihood of longer overall survival. The outcomes of resection for HCC have significantly improved in recent years compared with those in historical reports [47-49]. A review of overall survival after resection in patients selected for transplantation using the Milan criteria analyzed outcomes in 4,209 patients in whom the 5-year survival rate was $67 \%$ [50].

In view of the worldwide increase in the incidence of HCC, liver transplantation has gained importance as a treatment option. However, the shortage of deceased donor organs makes implementation of this option difficult in many cases. Because of the inherent risks to living donors, LDLT as a primary modality of treatment in this group of patients is controversial and continues to be debated [51]. These debates can only be resolved by well-conducted cost-utility studies.

\section{Conclusion}

Liver transplantation is an acceptable treatment option in selected patients with HCC and is the treatment of choice in patients with tumors defined within the Milan criteria with poor liver function. The lack of diagnostic tools for accurate preoperative prediction of tumor biology currently restricts our ability to identify all candidates who may benefit from liver transplantation.

\section{Conflict of Interest}

None of the authors have identified a conflict of interest or financial disclosures.

\section{References}

1 Poon RT, Fan ST, Lo CM, et al: Long-Term Survival and Pattern of Recurrence After Resection of Small Hepatocellular Carcinoma in Patients With Preserved Liver Function: Implications for a Strategy of Salvage Transplantation. Ann Surg 2002;235:373-382.

2 Belghiti J, Panis Y, Farges O, Benhamou JP, Fekete F: Intrahepatic recurrence after resection of hepatocellular carcinoma complicating cirrhosis. Ann Surg 1991;214:114-117.

3 Minagawa M, Makuuchi M, Takayama T, et al: Selection criteria for repeat hepatectomy in patients with recurrent hepatocellular carcinoma. Ann Surg 2003;238:703-710.

4 Starzl TE, Groth CG, Brettschneider L, et al: Orthotopic homotransplantations of the human liver. Ann Surg 1968;168:392-415. 
5 Starzl TE, Klintmalm GB, Porter KA, et al: Liver Transplantation with use of uyclosporin a and prednisone. N Engl J Med 1981;305:266-269.

6 Organ Procurement and Transplantation Network (OPTN). Transplant Annual Data Reports 2012. [Accessed: Aug 27, 2012](http://optn.transplant.hrsa.gov/data/annualreport.asp).

7 European Liver Transplant Registry. Mortality and Retransplantation. 2012. http://www.eltr.org/spip. php?article188 ([Accessed: Aug 27, 2012]).

8 Iwatsuki S, Gordon RD, Shaw BW, et al: Role of liver transplantation in cancer therapy. Ann Surg 1985;202:401-407.

9 Ringe B, Pichlmayr R, Wittekind C, et al: Surgical treatment of hepatocellular carcinoma: experience with liver resection and transplantation in 198 patients. World J Surg 1991;15:270-285.

10 Mazzaferro V, Regalia E, Doci R, et al: Liver transplantation for the treatment of small hepatocellular carcinomas in patients with cirrhosis. N Engl J Med 1996;334:693-699.

11 Llovet JM, Fuster J, Bruix J: Intention-to-treat analysis of surgical treatment for early hepatocellular carcinoma: Resection versus transplantation. Hepatology 1999;30:1434-1440.

12 Jonas S, Bechstein WO, Steinmüller T, et al: Vascular invasion and histopathologic grading determine outcome after liver transplantation for hepatocellular carcinoma in cirrhosis. Hepatology 2001;33:10801086.

13 Hwang S, Lee SG, Joh JW, et al: Liver transplantation for adult patients with hepatocellular carcinoma in Korea: Comparison between cadaveric donor and living donor liver transplantations. Liver Transpl 2005;11:1265-1272.

14 Duffy JP, Vardanian A, Benjamin E, et al: Liver transplantation criteria for hepatocellular carcinoma should be expanded. Ann Surg 2007;246:502-509.

15 Mazzaferro V, Bhoori S, Sposito C, et al: Milan criteria in liver transplantation for hepatocellular carcinoma: An evidence-based analysis of 15 years of experience. Liver Transpl 2011;17(Suppl 2):S44-S57.

16 Clavien PA, Lesurtel M, Bossuyt PM, et al: Recommendations for liver transplantation for hepatocellular carcinoma: an international consensus conference report. Lancet Oncol 2012;13:e11-e22.

17 Yao FY, Ferell L, Bass NM, et al: Liver transplantation for hepatocellular carcinoma: Expansion of the tumor size limits does not adversely impact survival. Hepatology 2001;33:1394-1403.

18 Sotiropoulos GC, Malagó M, Molmenti E, et al: transplantation realistic? Liver transplantation for hepatocellular carcinoma in cirrhosis: is clinical tumor classification before transplantation realistic? Transplantation 2005;79:483-487.

19 Parfitt JR, Marotta P, Alghamdi M, et al: Recurrent hepatocellular carcinoma after transplantation: Use of a pathological score on explanted livers to predict recurrence. Liver Transpl 2007;13:543-551.

20 Vauthey JN, Lauwers GY, Esnaola NF, et al: Simplified Staging for Hepatocellular Carcinoma. J Clin Oncol 2002;20:1527-1536.

21 Esnaola NF, Lauwers GY, Mirza NQ, et al: Predictors of Microvascular Invasion in Patients with Hepatocellular Carcinoma Who Are Candidates for Orthotopic Liver Transplantation. J Gastrointest Surg 2002;6:224-232.

22 Pawlik TM, Delman KA, Vauthey JN, et al: Tumor size predicts vascular invasion and histologic grade: Implications for selection of surgical treatment for hepatocellular carcinoma. Liver Transpl 2005;11:10861092.

23 Leung JY, Zhu AX, Gordon FD, et al: Liver transplantation outcomes for early-stage hepatocellular carcinoma: Results of a multicenter study. Liver Transpl 2004;10:1343-1354.

24 Marsh JW, Dvorchik I: Liver organ allocation for hepatocellular carcinoma: Are we sure? Liver Transpl 2003;9:693-696.

25 Decaens T, Roudot-Thoraval F, Hadni-Bresson S, et al: Impact of UCSF criteria according to pre- and postOLT tumor features: Analysis of 479 patients listed for HCC with a short waiting time. Liver Transpl 2006;12:1761-1769.

26 Yao FY, Xiao L, Bass NM, et al: Liver transplantation for hepatocellular carcinoma: Validation of the UCSFexpanded criteria based on preoperative imaging. Am J Transplant 2007;7:2587-2596.

27 Mazzaferro V, Llovet JM, Miceli R, et al: Predicting survival after liver transplantation in patients with hepatocellular carcinoma beyond the Milan criteria: a retrospective, exploratory analysis. Lancet Oncol 2009;10:35-43.

28 Metroticket calculator. [online] http://www.hcc-olt-metroticket.org/calculator/. [Accessed: 27 Aug 2012].

29 DuBay D, Sandroussi C, Sandhu L, et al: Liver transplantation for advanced hepatocellular carcinoma using poor tumor differentiation on biopsy as an exclusion criteria. Ann Surg 2011;253:166-172.

30 Cillo U, Vitale A, Bassanello M, et al: Liver transplantation for the treatment of moderately or well-differentiated hepatocellular carcinoma. Ann Surg 2004;239:150-159.

31 Colecchia A, Scaioli.E, Montrone L, et al: Pre-operative liver biopsy in cirrhotic patients with early hepatocellular carcinoma represents a safe and accurate diagnostic tool for tumour grading assessment. J Hepatol 2011;54:300-305.

32 Charpentier KP, Cheah YL, Machan JT, et al: Intention to treat survival following liver transplantation for hepatocellular carcinoma within a donor service area. HPB (oxford) 2008;10:412-415.

33 Pelletier SJ, Fu S, Thyagarajan V, et al: An intention-to-treat analysis of liver transplantation for hepatocellular carcinoma using organ procurement transplant network data. Liver Transpl 2009;15:859-868.

34 Marui Y, McCall J, Gane E, et al: Liver transplantation for hepatocellular carcinoma in New Zealand: a prospective intent-to-treat analysis. N Z Med J 2005;118:U1532-1545. 
35 Majno P, Lencioni R, Mornex F, et al: Is the treatment of hepatocellular carcinoma on the waiting list necessary? Liver Transpl 2011;17(Suppl 2):S98-S108.

36 Vakili K, Pomposelli JJ, Cheah YL, et al: Living donor liver transplantation for hepatocellular carcinoma: increased recurrence but improved survival. Liver Transpl 2009;15:1861-1866.

37 Lo CM, Fan ST, Liu CL, et al: Living donor versus deceased donor liver transplantation for early irresectable hepatocellular carcinoma. Br J Surg 2007;94:78-86.

38 Fisher RA, Kulik LM, Freise CE, et al: Hepatocellular carcinoma recurrence and death following living and deceased donor liver transplantation. Am J Transplant 2007;7:1601-1608.

39 Cronin DC, Millis JM, Siegler M: Transplantation of liver grafts from living donors into adults - too much, too soon. N Engl J Med 2001;344:1633-1637.

40 Barr ML, Belghiti J, Villamil FG, et al: A report of the Vancouver Forum on the care of the live organ donor: lung, liver, pancreas, and intestine data and medical guidelines. Transplantation 2006;81:1373-1385.

41 Lo CM: Complications and long-term outcome of living liver donors: a survey of 1508 cases in five Asian centers. Transplantation 2003;75:S12-S15.

42 Adam R, Macmaster P, O'Grady JG, et al: Evolution of liver transplantation in Europe: report of the European Liver Transplant Registry. Liver Transpl 2003;9:1231-1243.

43 Ghobrial RM, Freise CE, Trotter JF, et al: Donor morbidity after living donation for liver transplantation. Gastroenterology 2008;135:468-476.

44 Cheah YL, Simpson MA, Pomposelli JJ, et al: The incidence of death and potentially life-threatening "nearmiss" events in living donor hepatic lobectomy: a world-wide survey. Liver Transpl 2012; ( in press).

45 Bruix J, Sherman M: Management of hepatocellular carcinoma: An update. Hepatology 2011;53:1020-1022.

46 Omata M, Lesmana LA, Tateishi R, et al: Asian Pacific Association for the Study of the Liver consensus recommendations on hepatocellular carcinoma. Hepatol Int 2010;4:439-474.

47 Poon RT, Fan ST, Lo CM, et al: Improving survival results after resection of hepatocellular carcinoma: a prospective study of 377 patients over 10 years. Ann Surg 2001;234:63-70.

48 Fan ST, Mau Lo C, Poon RT, et al: Continuous improvement of survival outcomes of resection of hepatocellular carcinoma: a 20-year experience. Ann Surg 2011;253:745-758.

49 Grazi GL, Ercolani G, Pierangeli F, et al: Improved results of liver resection for hepatocellular carcinoma on cirrhosis give the procedure added value. Ann Surg 2001;234:71-78.

50 Lim KC, Chow PK, Allen JC, et al: Systematic review of outcomes of liver resection for early hepatocellular carcinoma within the Milan criteria. Br J Surg 2012;99:1623-1629.

51 Fuks D, Dokmak S, Paradis V, et al: Benefit of initial resection of hepatocellular carcinoma followed by transplantation in case of recurrence: an intention-to-treat analysis. Hepatology 2012;55:132-140. 